\title{
The antibody-based targeted delivery of TNF in combination with doxorubicin eradicates sarcomas in mice and confers protective immunity
}

\author{
T Hemmerle $^{1}$, P Probst ${ }^{1}$, L Giovannoni ${ }^{2}$, A J Green ${ }^{3}$, T Meyer $^{3}$ and D Neri ${ }^{\star}, 1$ \\ ${ }^{1}$ Department of Chemistry and Applied Biosciences, Swiss Federal Institute of Technology (ETH Zürich), Wolfgang-Pauli-Strasse 10, \\ CH-8093 Zürich, Switzerland; ${ }^{2}$ Philogen SpA, Località Bellaria 35, 53018 Sovicille (SI), Italy and ${ }^{3}$ UCL Cancer Institute, 72 Huntley \\ Street, London WC1B 6BT, UK
}

Background: Soft-tissue sarcomas are a group of malignancies of mesenchymal origin, which typically have a dismal prognosis if they reach the metastatic stage. The observation of rare spontaneous remissions in patients suffering from concomitant bacterial infections had triggered the clinical investigation of the use of heat-killed bacteria as therapeutic agents (Coley's toxin), which induced complete responses in patients in the pre-chemotherapy era and is now known to mediate substantial elevations in serum TNF levels.

Methods: We designed and developed a novel immunocytokine based on murine TNF sequentially fused to the antibody fragment F8 (specific to extra-domain A of fibronectin). The antitumor activity was studied in two syngeneic murine sarcoma models.

Results: The L19 antibody (specific to extra-domain B of fibronectin) has shown by SPECT imaging procedures to selectively localise on sarcoma in a patient with a peripheral nerve sheath tumour, and immunohistochemical analysis of human soft-tissue sarcoma samples showed comparable antigen expression of EDA and EDB. The antibody-based pharmacodelivery of TNF by the fusion protein 'F8-TNF' to oncofetal fibronectin in sarcoma-bearing mice leads to complete and long-lasting tumour eradications when administered in combination with doxorubicin, the first-line drug for the treatment of sarcomas in humans. Doxorubicin alone did not display any therapeutic effect in both tested models of this study. The cured mice had acquired protective immunity against the tumour, as they rejected subsequent challenges with sarcoma cells.

Conclusion: The findings of this study provide a rationale for the clinical study of the fully human immunocytokine L19-TNF in combination with doxorubicin in patients with soft-tissue sarcoma.

Sarcomas are rare tumours and represent a heterogeneous group of cancers that stem from soft tissue, bone, cartilage, peripheral nerve sheets or from other connective tissues. Many of these tumours affect children and young adults, accounting for $15 \%$ of all paediatric cancers. Most sarcomas originate from non-epithelial extraskeletal tissue and are called soft-tissue sarcoma. For localised disease, surgical resection represents a potentially curative therapy, but this is often limited by anatomical constraints. Additionally, soft-tissue sarcomas have a high recurrence rate (Clark et al, 2005; Scoggins and Pisters, 2008).

In the metastatic stage of soft-tissue sarcoma and depending on histological sub-type, chemotherapy is administered as first-line 
treatment, but the median survival is only 8-12 months. The anthracycline derivate doxorubicin (Adriamycin) is used as a standard-of-care drug in sarcoma with a response rate of $12-30 \%$. Commonly, doxorubicin is administered in combination with ifosfamide or dacarbazine, which enhances the response rates, but does not lead to a significant survival benefit compared to the monotherapy (Pisters, 2007; Riedel, 2012). These combination treatments are associated with substantial toxicities and a median duration of responses in the order of months. Thus, there is a clear need of improved agents for the therapy of soft-tissue sarcomas.

More than 100 years ago, the New York surgeon William B Coley had observed a case of spontaneous sarcoma regression as a consequence of an erysipelas infection. This observation triggered the development of 'Coley's toxin' (a mixture of heat-inactivated bacteria), which induced high fever in patients, but also a reasonable chance of long-term survival (Starnes, 1992). We now know that endotoxin treatment can be efficacious against certain types of immunogenic tumours (Berendt et al, 1978) and that Coley's toxin treatment induced a dramatic elevation of TNF (Starnes, 1992). Indeed, for reasons that are still not completely understood but are probably related to the immunogenic nature of sarcoma-associated antigens, sarcomas appeared to respond much better to Coley's toxin treatment compared to other tumour types (Starnes, 1992).

Systemic treatment of cancer patients with recombinant human TNF showed that this pro-inflammatory cytokine can only be tolerated at a very low dose (MTD of $300 \mu \mathrm{g} \mathrm{m}^{-2}$ ). In spite of the occurrence of severe hypotension and organ failure events, tumour regressions were rarely observed (Lejeune et al, 2006). However, recombinant human TNF (Beromun) has been found to be efficacious for the treatment of patients with large sarcomas of the limb, who are candidates for amputation, in the isolated limb perfusion procedure, with response rates up to $80 \%$ (Eggermont et al, 1997). The product is frequently administered in combination with melphalan and mild hyperthermia.

The therapeutic activity of pro-inflammatory cytokines is often hindered by substantial toxicity at low doses, which prevents the escalation to therapeutically active doses. However, recent research has shown that suitable tumour-targeting antibodies can be used for the construction of 'immunocytokine' fusion proteins and can mediate the selective delivery of cytokines to the site of disease (Kontermann, 2012; Pasche and Neri, 2012). Curnis et al (2002) investigated the therapeutic potential of recombinant human TNF fused to an NGR peptide that mediates a preferential localisation of the protein at sites of tumour neo-vasculature, as assessed by microscopic analysis of tissue sections. The corresponding murine NGR-TNF fusion protein was tested in combination with doxorubicin in mouse models of melanoma, mammary adenocarcinoma, prostate cancer and lymphoma (Bertilaccio et al, 2008), leading to the observation of additive therapeutic effects but no tumour eradication. The human NGR-TNF fusion protein is currently being studied by MolMed in combination with doxorubicin in a randomized Phase II clinical trial in patients with soft-tissue sarcoma (NCT00484341) (Ferrari et al, 2013).

We have previously described the immunocytokine L19-TNF, consisting of the fully human antibody fragment L19 (specific to the alternatively spliced EDB domain of fibronectin, a marker of angiogenesis) fused to TNF (Borsi et al, 2003). The fusion protein based on murine TNF mediated a potent therapeutic effect in mice bearing murine sarcomas or colon carcinomas when used in combination with melphalan (Borsi et al, 2003; Balza et al, 2006). At the immunological level, the treatment led to a highly efficient priming of $\mathrm{CD} 4+\mathrm{T}$ cells and consequent activation and maturation of CD8 + CTL effector cells, as demonstrated by in vivo depletion and adoptive cell-transfer experiments (Mortara et al, 2007). Complete tumour eradications were also observed when L19-TNF was combined with a second immunocytokine,
L19-IL2, for the treatment of mouse models of neuroblastoma and teratocarcinoma (Borsi et al, 2003; Balza et al, 2010).

The fully human L19-TNF fusion protein, containing human TNF, has been tested in a Phase I/II monotherapy clinical trial (Spitaleri et al, 2013) and in a Phase II clinical trial in patients with metastatic melanoma of the limb in the isolated limb perfusion setting (Papadia et al, 2012), in combination with melphalan.

Melphalan is not commonly used for the systemic therapy of sarcoma and there is a need to learn about the clinical potential of the combination of L19-TNF with doxorubicin (the drug of choice for first-line treatment of most soft-tissue sarcomas). Moreover, it remains unclear whether it is better to use the F8 (specific to the EDA domain of fibronectin) or L19 (specific to EDB) for tumour-targeting applications (Schliemann et al, 2009; Berndt et al, 2010; Frey et al, 2011; Schwager et al, 2011). To address these issues in a preclinical model, we performed a comparative immunohistochemical analysis of the two antibodies on sarcoma specimens. In addition, we studied the therapeutic performance of a murine TNF-based immunocytokine specific to EDA-positive fibronectin (termed F8-TNF), alone or in combination with doxorubicin in two syngeneic immunocompetent mouse models of sarcoma. F8-TNF, when used in combination with doxorubicin, led to complete and long-lasting tumour eradications in both the models. Interestingly, the cured mice had acquired an antitumour immunity, as they rejected subsequent challenges with sarcoma cell lines. Nuclear medicine information (for example, SPECT-CT) about the tumour-targeting performance of the F8 antibody in patients is still missing. However, the opportunity to use the TNF-based immunocytokines specific to oncofetal fibronectin in patients with sarcoma is supported by the fact that a radiolabelled preparation of the L19 antibody was shown to selectively localise to sarcoma lesions in a patient.

MATERIALS AND METHODS

Cell lines and tumour models. CHO cells (ATCC-LCG, Molsheim Cedex, France), LM-fibroblasts (ATCC-LCG) and the murine tumour cell lines F9 teratocarcinoma (ATCC-LCG), WEHI-164 Sarcoma (ATCC-LCG) and Sarcoma 180 (CLS, Eppelheim, Germany) fibrosarcoma were cultured according to the supplier's protocol.

For tumour models, 10-12-week-old female 129/SvEv mice and ICR mice were obtained from Charles River (Sulzfeld, Germany) and female Balb/c mice were obtained from Janvier (Le Genest Saint Isle, France). Tumour cells were implanted subcutaneously in the flank using $25 \times 10^{6}$ cells (F9), $3 \times 10^{6}$ cells (WEHI-164) and $10 \times 10^{6}$ cells (Sarcoma 180). Animals were killed when tumour volumes reached a maximum of $2000 \mathrm{~mm}^{3}$. Experiments were performed under a project license granted by the Veterinäramt des Kantons Zürich, Switzerland (169/2008, 42/2012).

Nuclear medicine studies. As part of a larger radioimmunotherapy clinical trial open to patients with various types of malignancies (Eudra-CT Number 2007-007241-12) investigating the use of the L19 antibody in SIP format and labelled with iodine131 (Sauer et al, 2009; Erba et al, 2012), we studied one patient with a high-grade sarcoma (malignant peripheral nerve sheath tumour). SIP(L19) was radioiodinated as described (Erba et al, 2012) and administered to the patient by intravenous injection at a dose of $4 \mathrm{mg}$ and $213 \mathrm{mCi}$.

Images were acquired on a GE Infinia Hawkeye 4 SPECT-CT system (GE Healthcare, Bucks, UK) at 24, 48, 72 and $144 \mathrm{~h}$ post injection. Transaxial images were reconstructed by OS-EM using CT-based attenuation correction and triple-energy window scatter correction. Regions of interest were drawn over tumour and normal tissue regions on the CT images (three slices per tissue) and 
transferred to the corresponding SPECT images for data extraction (counts per voxel) for relative uptake estimation.

Immunofluorescence analysis of antigen expression in sarcoma. Frozen human sarcoma samples from OriGene Technologies (Rockville, MD, USA) and 10- $\mu \mathrm{m}$ cryostat sections of WEHI-164 and Sarcoma 180 tumours were fixed in ice-cold acetone and stained for antigen expression either with primary biotinylated antibodies in small immunoprotein (SIP) format of F8, L19 and KSF (negative control, specific to egg lysozyme) or biotinylated F8-TNF (final concentration of $2 \mu \mathrm{g} \mathrm{ml}^{-1}$ ). Binding was detected with streptavidin-Alexa Fluor 488 complex (Biospa, Milan, Italy).

Cloning, expression and protein in vitro characterisation. F8-TNF is a fusion protein consisting of the F8 antibody (specific to the alternatively spliced EDA domain of fibronectin (Villa et al, 2008)) in scFv format, sequentially fused to murine tumour-necrosis factor alpha (gene from Source BioScience, Nottingham, UK) by the 15-amino-acid linker (SSSSG)3. The genes for the F8 antibody and TNF were PCR-amplified, PCR-assembled and cloned into the mammalian cell expression vector pcDNA3.1 $(+)$ (Invitrogen, Zug, Switzerland) by a HindIII/NotI restriction site (sequence of F8-TNF is shown in Supplementary Material 1). The fusion protein was expressed by $\mathrm{CHO}$ cells from a stable monoclonal cell line (as previously described (Sacchi et al, 2004)) and purified to homogeneity by protein A chromatography (Hoogenboom and Winter, 1992). The purified protein was analysed using SDS-PAGE, size-exclusion chromatography (Superdex200 10/300GL, GE Healthcare, Freiburg, Germany) and BIAcore on an EDA antigen-coated sensor chip (Borsi et al, 1998; Villa et al, 2008). The biological activity of murine TNF was determined by incubation with mouse LM fibroblasts (ATCC), in the presence of $2 \mu \mathrm{g} \mathrm{ml}^{-1}$ actinomycin D (Sigma-Aldrich, Buchs, Switzerland) as described by Borsi et al (2003). The cytotoxic potential of F8-TNF on different tumour cell lines was tested in vitro using different cytotoxicity assays. In 96-well plates, the cells were incubated in medium supplemented with $2 \mu \mathrm{g} \mathrm{ml}^{-1}$ actinomycin D and varying concentrations of recombinant murine TNF (eBioscience, San Diego, CA, USA) or F8-TNF. After $24 \mathrm{~h}$ at $37^{\circ} \mathrm{C}$, cell viability was determined with Cell Titer Aqueous One Solution (Promega, Dübendorf, Switzerland). Results were expressed as the percentage of cell viability compared to cells treated with actinomycin $\mathrm{D}$ only.

Biodistribution studies. The in vivo targeting was assessed by quantitative biodistribution as previously described (Pasche et al, 2011). Radioiodinated F8-TNF ( $3 \mu \mathrm{g}$ ) were injected i.v. into the lateral tail vein of tumour-bearing mice. Mice were killed $24 \mathrm{~h}$ after injection, and their organs were excised, weighed and radioactivity was measured using a Cobra $\gamma$ counter (Packard, Meriden, CT, USA). The radioactivity of organs and tumours was expressed as the percentage of injected dose per gram of tissue (\%ID/ $\mathrm{g} \pm$ standard error).

Therapy studies. When tumours were clearly palpable, mice were randomly grouped $(n=5)$ and received three injections i.v. into the lateral tail vein. PBS ( $\left.5 \mathrm{mg} \mathrm{kg}^{-1}\right)$, Doxorubicin ( $\left.2 \mu \mathrm{g} \mathrm{F} 8-\mathrm{TNF}\right)$ or the combination was administered every $48 \mathrm{~h}$. The mice were monitored daily and tumour volume was determined by measuring the diameters with a caliper (volume $=0.5 \times$ length $\times$ width $^{2}$ ). For re-challenge experiments, cured mice were injected subcutaneously with $3 \times 10^{6}$ WEHI- 164 cells and $10 \times 10^{6}$ Sarcoma 180 cells in the flank.

Ex vivo immunofluorescence analysis of therapy. For the ex vivo detection of targeting, the mice were injected according to the therapy schedule and tumours were excised 2 days after the final injection. The tumours were embedded in cryoembedding medium (Thermo Scientific, Rockford, IL, USA) and cryostat sections $(10 \mu \mathrm{m})$ were stained using the antibodies rat anti-murine TNF
(eBioscience) and anti-rat Alexa Fluor 488-coupled secondary antibody (Invitrogen). For vascular staining, goat anti-CD31 (Santa Cruz, Heidelberg, Germany) and anti-goat Alexa Fluor 594-coupled secondary antibody (Invitrogen) were used. Slides were mounted with fluorescent mounting medium (Dako, Glostrup, Denmark) and analysed with an Axioskop2 mot plus microscope (Zeiss, Feldbach, Switzerland).

Statistical analysis. Data are expressed as the mean ( \pm s.e.m.). Differences in tumour volume between therapeutic groups were compared using the repeated measures (mixed model) ANOVA analysis with Bonferroni post-test of Graphpad Prism (La Jolla, CA, USA).

\section{RESULTS}

Nuclear medicine data. As part of a broader characterisation of the tumour-targeting performance of the L19 antibody in patients with various types of cancer (Santimaria et al, 2003; Sauer et al, 2009; Erba et al, 2012), we studied the accumulation of this antibody in SIP format (Borsi et al, 2003; Berndorff et al, 2005) in a patient with a high-grade sarcoma that was refractory to conventional therapy. The patient had metastatic disease in his lung and bones. Figure 1 shows an expansile metastatic deposit in the apex of the right lung infiltrating the second rib, as seen on CT. The deposit was also FDG-avid as evidenced by FDG-PET imaging. Highly selective uptake of ${ }^{131} \mathrm{I}-\mathrm{SIP}(\mathrm{L} 19)$ could be observed 48,72 and $144 \mathrm{~h}$ following antibody administration by intravenous bolus injection. The cumulated uptake (area under the time activity curve) of the L19 antibody was greater in tumour than in liver and kidney (clearance-related organs that often exhibit a higher antibody uptake compared to other tissues).

Oncofetal fibronectin expression in human and murine sarcoma. Freshly frozen tissue samples from sarcoma patients and murine sarcomas were analysed for the expression of oncofetal fibronectin as an antigen. Figure 2 presents representative immunofluorescence findings of tumour sections stained with L19, F8 and KSF antibody (specific to hen egg lysozyme and used here as negative control). Human sarcomas and WEHI-164 sarcoma exhibited comparable staining levels for the two antibodies, whereas F8 showed a more intense staining in the experimental mouse model Sarcoma 180. Based on these results, we decided to focus our preclinical work on the immunocytokine F8-TNF.

Immunocytokine production and characterisation. The fusion protein F8-TNF, consisting of the F8 antibody in $\mathrm{scFv}$ format (Villa et al, 2008) sequentially fused to murine TNF with a 15-amino-acid linker (Borsi et al, 2003), was expressed in $\mathrm{CHO}$ cells and purified to homogeneity by Protein A chromatography, followed by gel-filtration (monomer: $44 \mathrm{kDa}$, non-covalent homotrimer: $132 \mathrm{kDa}$ ) (Figure $3 \mathrm{~A}$ and $\mathrm{B}$ ). The fusion protein eluted as a single peak of the correct size in analytical size-exclusion chromatography (Figure 3C) and exhibited a high functional affinity and kinetic stability towards the cognate antigen immobilised on a BIAcore microsensor chip with an apparent $K_{\mathrm{D}}$ of $1 \mathrm{~nm}$ (Figure $3 \mathrm{D}$ ). The apparent $K_{\mathrm{D}}$ of $1 \mathrm{~nm}$ reflects the avidity of the trimereic fusion protein. The biological TNF activity of F8-TNF was assessed by a cell cytotoxicity assay on murine LM fibroblasts (Borsi et al, 2003) and on the murine sarcoma cell lines WEHI-164 and sarcoma 180, revealing an in vitro potency comparable to the one of recombinant murine TNF (Figure 3E). The fusion protein, labelled with iodine-125, was also studied by quantitative biodistribution assay in mice bearing subcutaneously grafted F9 teratocarcinomas, WEHI-164 and sarcoma 180 (Figure $3 \mathrm{~F}$ ), confirming a preferential accumulation at the tumour 
A

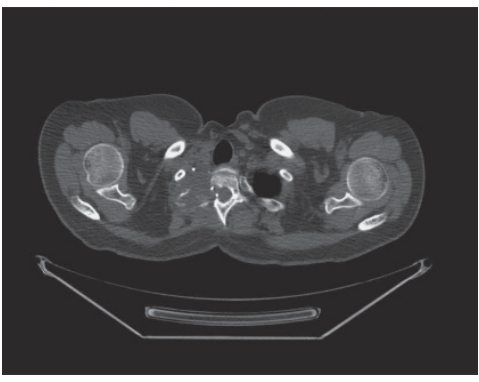

B

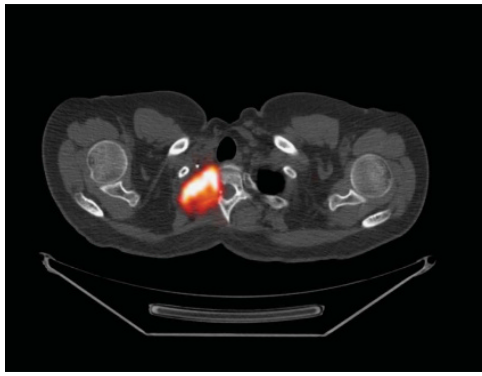

C
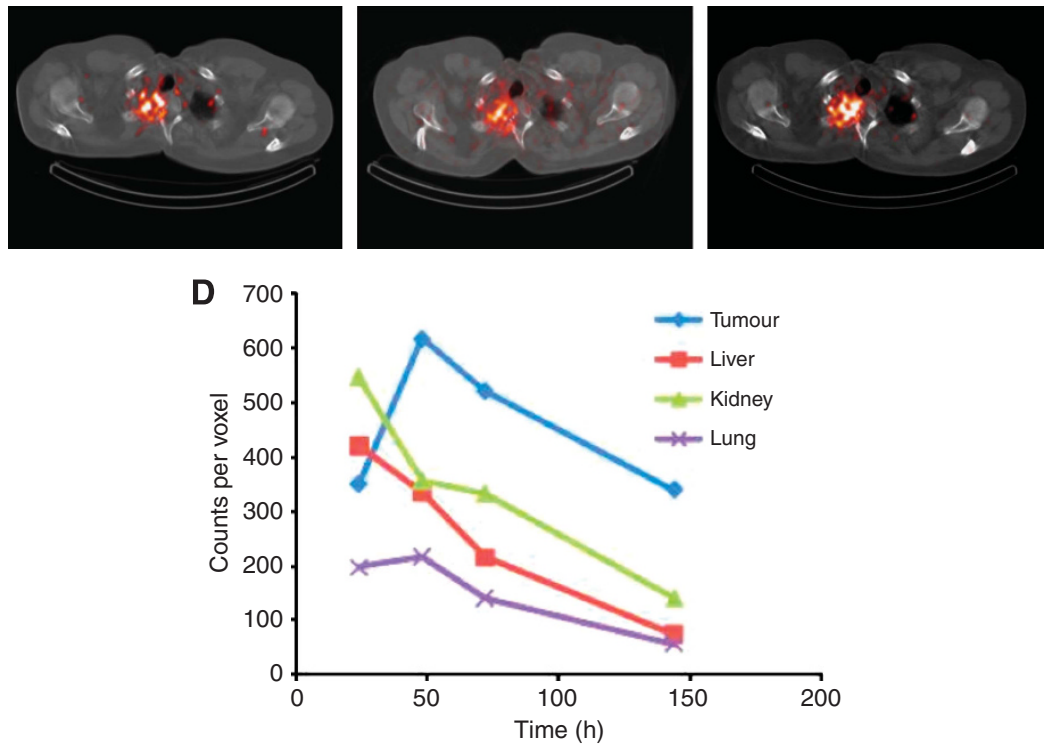

Figure 1. Imaging studies of a patient with metastatic sarcoma. (A) Transaxial projection of a CT scan. (B) FDG-PET-CT analysis of the same section. (C) Composite SPECT-CT transactial sections, imaged $48 \mathrm{~h}, 72 \mathrm{~h}$ and $144 \mathrm{~h}$ following intravenous administration of ${ }^{131} \mathrm{I}-\mathrm{SIP}(\mathrm{L} 19)$ (4 mg, $213 \mathrm{mCi}$ ). (D) Dosimetric evaluation of the radioactivity counts in regions of interest of comparable sizes, drawn in tumour, liver, kidney and lung at various time points.

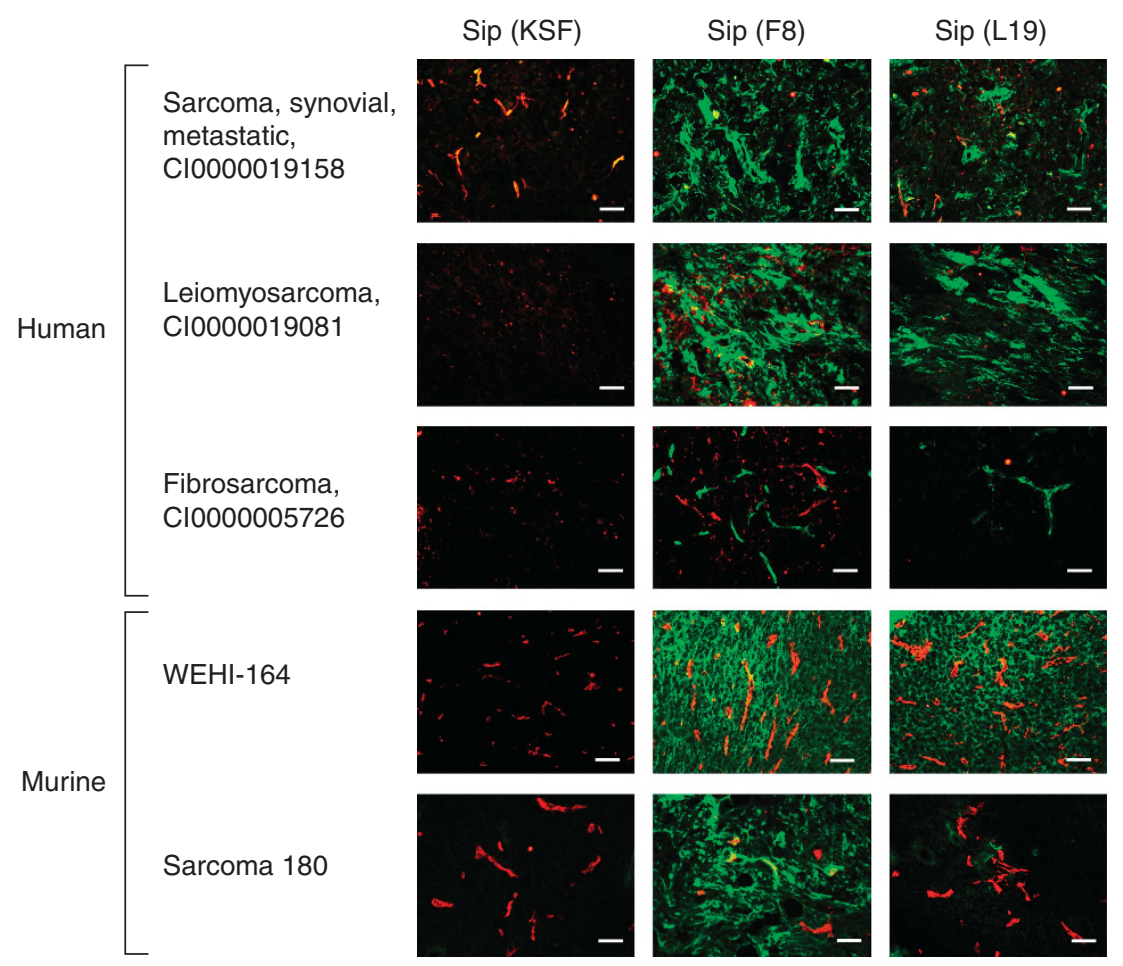

Figure 2. Analysis of antigen expression by immunofluorescence of freshly frozen human (diagnosis and case ID) and murine sarcoma tissue samples with biotinylated antibody in SIP format (green, Alexa Fluor 488) and goat anti-CD31 antibody (red, Alexa Fluor 594 ). × 20 magnification, scale bars $=100 \mu \mathrm{m}$. 
A

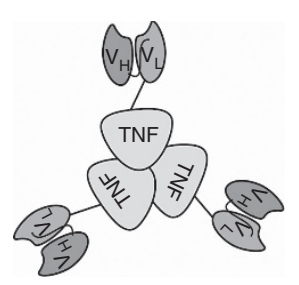

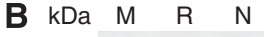

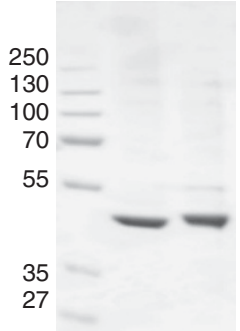

C

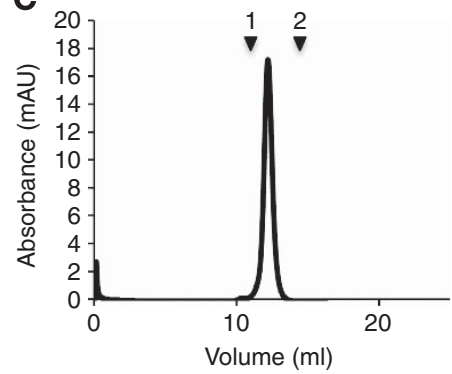

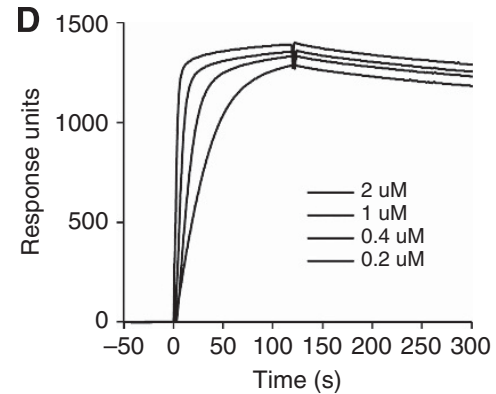

E
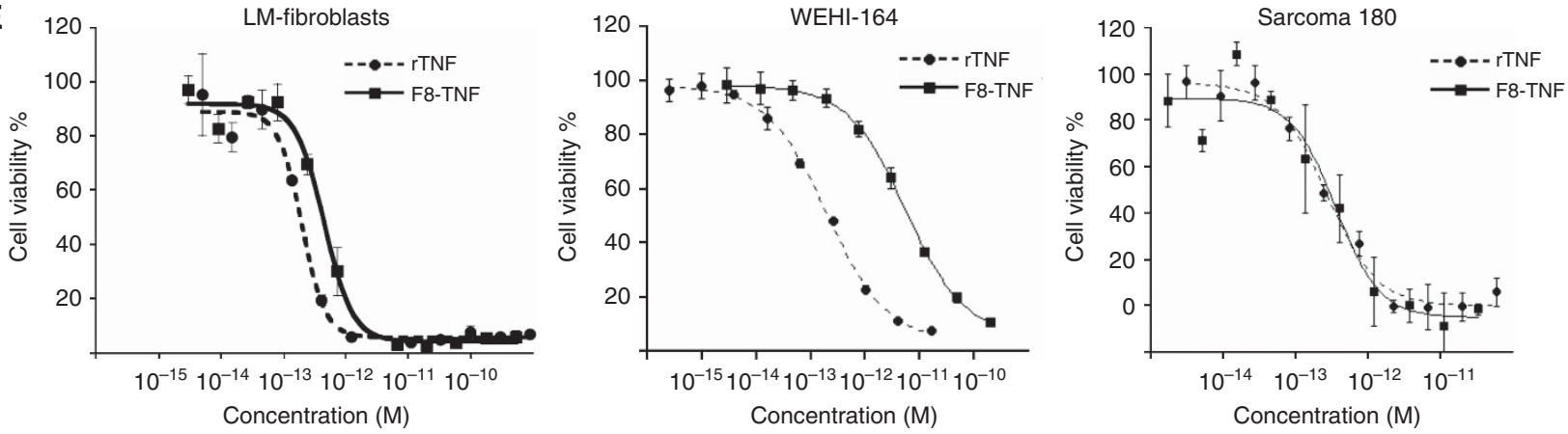

$\mathbf{F}$
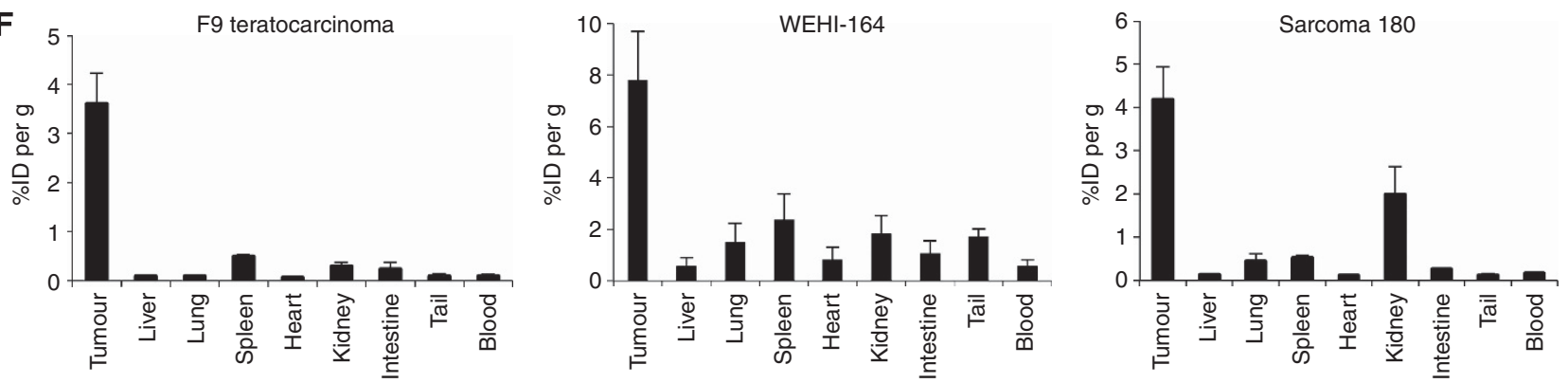

Figure 3. Cloning, expression and characterisation of F8-TNF. (A) Schematic representation of the domain assembly of F8-TNF in non-covalent trimeric format. (B) SDS-PAGE analysis of purified fusion protein: $M$, molecular marker; $N$, non-reducing; $R$, reducing conditions. (C) Size-exclusion chromatography profile of purified F8-TNF trimer (132 kDa, $12.6 \mathrm{ml}$ retention volume; 1 , ferritin $440 \mathrm{kDa}, 11 \mathrm{ml} ; 2, \mathrm{BSA} 67 \mathrm{kDa}, 14.1 \mathrm{ml})$.

(D) BIAcore analysis of the fusion protein on an EDA-coated CM5 sensor chip. (E) Cytotoxicity assays of F8-TNF and recombinant murine TNF against LM-fibroblasts (IC 50 rTNF: $2 \times 10^{-13} \mathrm{M}$; IC 50 F8-TNF: $\left.4 \times 10^{-13} \mathrm{M}\right)$, WEHI-164 (IC 50 rTNF: $2 \times 10^{-13} \mathrm{M}$; IC 50 F8-TNF: $\left.5 \times 10^{-12} \mathrm{M}\right)$ and Sarcoma 180 cells $\left(I_{50}\right.$ rTNF: $3 \times 10^{-13} ; I_{50}$ F8-TNF: $\left.4 \times 10^{-13}\right)$. (F) Biodistribution results obtained $24 \mathrm{~h}$ after the i.v. administration of $3 \mu \mathrm{g}$ of radioiodinated F8-TNF to tumour-bearing mice (F9 teratocarcinoma, WEHI-164 fibrosarcoma, Sarcoma 180). Organs were excised and radioactivity counted. Results are expressed as percent of injected dose per gram of tissue (\% ID per gram \pm s.e.).

site $24 \mathrm{~h}$ after intravenous injection, with tumour-to-blood ratios of 37,13 and 25 , respectively.

The selective immunofluorescence staining of WEHI-164 and sarcoma 180 with F8-TNF on tumour sections ex vivo and following intravenous administration is shown in Supplementary Material 2 and reveals an accumulation of the fusion protein not only on tumour neo-vasculature, but also on sarcoma cells.

Therapy studies. We studied the therapeutic activity of intravenous administrations of F8-TNF $(2 \mu \mathrm{g})$, doxorubicin $\left(5 \mathrm{mg} \mathrm{kg}^{-1}\right)$ or the combination of the two agents at the recommended dose in immunocompetent mice bearing WEHI-164 sarcoma (Figure 4) and 180 sarcoma (Figure 5). The dose of doxorubicin was chosen on the basis of previous studies performed in other groups (Arap et al, 1998) and in our own lab (Ebbinghaus et al, 2005; Marlind et al, 2008). In both models, doxorubicin treatment did not induce any significant anticancer activity. F8-TNF as a single agent exhibited a potent tumour growth inhibition compared to the saline control group $(P<0.0001$; the statistical analysis is presented in Supplementary Material 3), resulting in complete cures of $40 \%$ of the animals. The combination therapy of F8-TNF with doxorubicin led to an enhanced antitumour effect and to complete tumour eradications (four out of five mice and five out of five mice in WEHI-164 and 180 sarcomas, respectively).

Treatments were very well tolerated, except for the combination treatment group of F8-TNF with doxorubicin against WEHI-164 tumours, where mice exhibited weight loss up to $15 \%$. Mice fully recovered weight after the treatment cycle was finished (Supplementary Material 4). At present, it is not clear why weight loss in the combination treatment group was observed in the WEHI-164 model but not in the 180 sarcoma model.

Cured mice were re-challenged by the subcutaneous injection of tumour cells $>50$ days after the end of therapy. Interestingly, tumour lesions did not grow, indicating that the treatment had led to an antitumour immune protection against the sarcoma. Similarly, a second subsequent re-challenge with sarcoma cells, performed $>100$ days after the end of therapy, did not lead to tumour formation, indicating that the antisarcoma vaccination effect was durable.

Tumours from mice treated with F8-TNF turned black few hours after injection. In parallel experiments, the histological analysis of tumour sections after treatment revealed the formation 


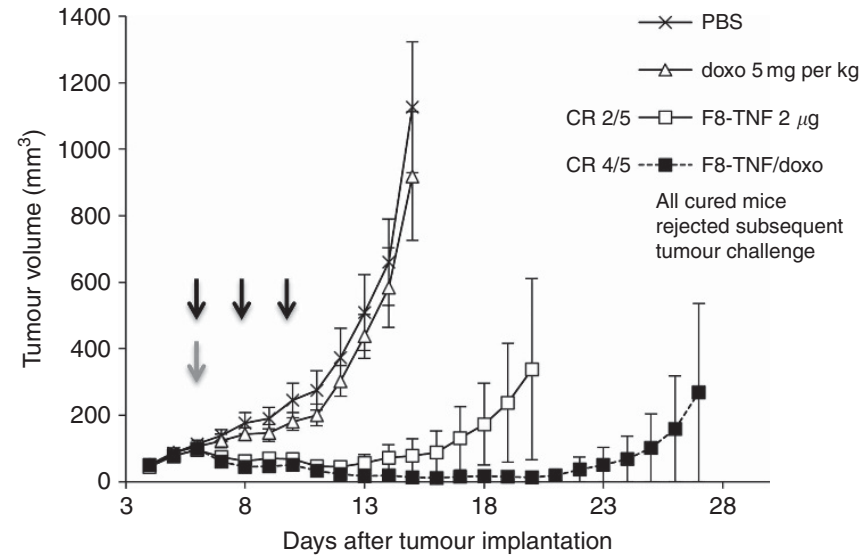

Figure 4. Therapeutic activity of F8-TNF and doxorubicin in monoand combination therapy against established subcutaneous murine WEHI-164 sarcoma. Mice received intravenously a single injection of $5 \mathrm{mg} \mathrm{kg}^{-1}$ doxorubicin, three injections of $2 \mu \mathrm{g}$ F8-TNF or the combination (injections are indicated by arrows. grey, doxorubicin; black, F8-TNF). Phosphate-buffered saline (PBS) was used as a vehicle. Treatment was repeated every $48 \mathrm{~h}$ (CR, complete response). After 50 and 150 days, cured mice were injected with tumour cells to check for immune protection against sarcoma. Data represent mean tumour volumes ( \pm s.e.m.), $n=5$ mice per group.

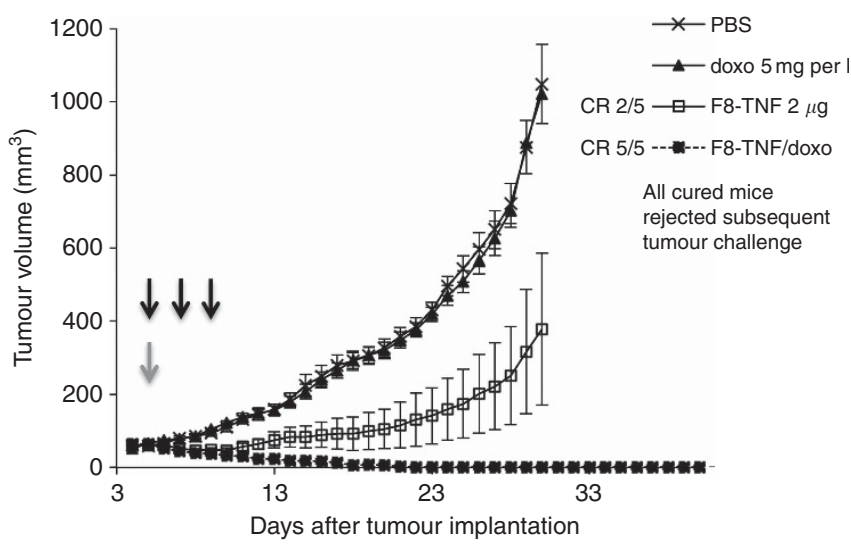

Figure 5. Therapeutic activity of F8-TNF and doxorubicin in monoand combination therapy against established subcutaneous murine Sarcoma 180. Treatment was started when tumours reached a size of $70 \mathrm{~mm}^{3}$ and mice received i.v. injections on days 5, 7 and 9 after tumour implantation of either $5 \mathrm{mg} \mathrm{kg}^{-1}$ doxorubicin ( $\left.\mathbf{\Lambda}\right), 2 \mu \mathrm{g}$ F8-TNF ( $\square), 2 \mu \mathrm{g}$ F8-TNF followed by $5 \mathrm{mg} \mathrm{kg}^{-1}$ doxorubicin ( $\mathbf{\square}$ ) or PBS as a control $(x)(C R$, complete response). Injections are indicated by arrows (grey, doxorubicin; black, F8-TNF). After 50 and 100 days, cured mice were re-challenged by s.c. injection of Sarcoma 180 cells. Data represent mean tumour volumes (+s.e.m.), n=5 mice per group.

of massive necrosis within the neoplastic mass already 4 hours after the administration of F8-TNF (Supplementary Material 5).

\section{DISCUSSION}

In this study, we presented evidence for abundant expression of oncofetal fibronectin (containing the alternatively spliced EDA and EDB domains) in the samples of murine sarcomas and human specimens. Furthermore, we provided initial evidence supporting the ability of the L19 antibody (specific to the EDB domain of fibronectin) to selectively localise to sarcoma lesions in patients. The same antibody has been used to image $>200$ patients with various types of malignancies (Santimaria et al, 2003; Sauer et al, 2009; Erba et al, 2012), whereas the F8 antibody (which has been isolated more recently; Villa et al, 2008) has not yet been investigated in nuclear medicine studies.

Some non-pathogenic bacterial strains, which are able to grow and accumulate in tumours, but not in normal healthy tissue, have been considered for a local induction of pro-inflammatory cytokines (for example, TNF) and for the delivery of drug-activating enzymes (Pawelek et al, 1997; Bermudes et al, 2001; Dang et al, 2001). While these anaerobic bacteria can only accumulate in a tumour that has a necrotic core, antibody-based pharmacodelivery strategies (for example, immunocytokines) are probably more versatile, both in terms of possible payloads and in terms of in vivo targeting (tumour cells, tumour stroma and tumour neo-vasculature). Recently, the use of antibody-modified engineered Salmonella strains has been proposed for antitumour applications, with very promising results in mouse models of cancer (Massa et al, 2013).

The fully human immunocytokine L19-TNF has been studied in two Phase I/II clinical trials in patients with cancer, but could not be used in this study, as human TNF does not cross-react with the murine receptor. We used F8-TNF (containing the murine version of the cytokine) for the preclinical characterisation of the therapeutic potential associated to the targeted delivery of TNF to oncofetal fibronectin. F8-TNF eradicated sarcomas in almost all treated animals in two murine immunocompetent models of the disease, when the agent was administered in combination with doxorubicin. By contrast, this chemotherapeutic agent did not mediate any detectable anticancer activity, when used as monotherapy at the recommended dose of $5 \mathrm{mg} \mathrm{kg}^{-1}$. The immunocytokine not only eradicated tumours, but also vaccinated mice against two subsequent challenges with sarcoma cells.

The synergistic therapeutic benefit in the combined use of proinflammatory immunocytokines and cytotoxic drugs may depend on several parameters, including the administration schedule, the modulation of antibody uptake at the tumour site, the selective damage to the endothelium and the activation or repression of specific immune cell subtypes (Moschetta et al, 2012). Previous experiments with L19-TNF have shown that the TNF-based immune response is primarly mediated by $\mathrm{CD} 8+\mathrm{T}$ cells and NK cells (Balza et al, 2006). Innovative methodologies, such as high-throughput tetramer technology (Kita et al, 2003) and HLA-peptidome analysis (Bassani-Sternberg et al, 2010) may help identify the targets of a polyclonal T-cell response.

Murine sarcomas treated with F8-TNF turned black after treatment. This is reminiscent of scab formation and tumour eradication, previously observed by our group for the antibodybased targeted delivery of truncated tissue factor (Nilsson et al, 2001) or photosensitizers (Palumbo et al, 2011) to oncofetal fibronectin in the tumour sub-endothelial extracellular matrix. These findings are in line with the ability of TNF to induce potent intravascular coagulation of tumour blood vessels, previously reported for the use of recombinant TNF in isolated limb perfusion procedures (Olieman et al, 1997).

The results presented in this study reinforce the use of TNF for cancer therapy and provide a rationale for the clinical evaluation of targeted TNF in combination with doxorubicin in the treatment of patients with soft-tissue sarcoma. While both EDA and EDB domain of fibronectin could be considered as targets for the pharmacodelivery of TNF, our immediate clinical plans feature the use of L19-TNF as therapeutic agent, as the product has already completed Phase I monotherapy studies (Spitaleri et al, 2013), and as the tumour-targeting performance of the L19 antibody has been studied in $>200$ patients with cancer (Santimaria et al, 2003; Sauer et al, 2009; Tijink et al, 2009; Erba et al, 2012). The selective uptake 
of SIP(L19) in sarcoma lesions, as presented in this paper, has led to the beginning of a Phase Ib/II clinical trial, featuring the administration of escalating doses of L19-TNF in combination with $75 \mathrm{mg} \mathrm{m}^{-2}$ doxorubicin (once every 3 weeks; EUDRA-CT 2012-000950-75).

\section{ACKNOWLEDGEMENTS}

Financial contributions from the Swiss National Science Foundation, the ETH Zürich, the Commission for Technology and Innovation (CTI) Switzerland, the Swiss Cancer League and the European Union (FP7 Project PRIAT) are gratefully acknowledged. The ${ }^{131}$ I-SIP(L19) trial was undertaken in the NIHR UCLH Clinical Research Facility and supported by the UCL Experimental Cancer Medicine Centre.

\section{CONFLICT OF INTEREST}

$\mathrm{DN}$ is founder and shareholder of Philogen SpA (Siena, Italy), the biotech company that owns the F8 antibody. The remaining authors declare no conflict of interest.

\section{REFERENCES}

Arap W, Pasqualini R, Ruoslahti E (1998) Cancer treatment by targeted drug delivery to tumor vasculature in a mouse model. Science 279(5349): 377-380.

Balza E, Carnemolla B, Mortara L, Castellani P, Soncini D, Accolla RS, Borsi L (2010) Therapy-induced antitumor vaccination in neuroblastomas by the combined targeting of IL-2 and TNFalpha. Int J Cancer 127(1): 101-110.

Balza E, Mortara L, Sassi F, Monteghirfo S, Carnemolla B, Castellani P, Neri D, Accolla RS, Zardi L, Borsi L (2006) Targeted delivery of tumor necrosis factor-alpha to tumor vessels induces a therapeutic $\mathrm{T}$ cell-mediated immune response that protects the host against syngeneic tumors of different histologic origin. Clin Cancer Res 12(8): 2575-2582.

Bassani-Sternberg M, Barnea E, Beer I, Avivi I, Katz T, Admon A (2010) Soluble plasma HLA peptidome as a potential source for cancer biomarkers. Proc Natl Acad Sci USA 107(44): 18769-18776.

Berendt MJ, North RJ, Kirstein DP (1978) The immunological basis of endotoxin-induced tumor regression. Requirement for T-cell-mediated immunity. J Exp Med 148(6): 1550-1559.

Bermudes D, Low KB, Pawelek J, Feng M, Belcourt M, Zheng LM, King I (2001) Tumour-selective Salmonella-based cancer therapy. Biotechnol Genet Eng Rev 18: 219-233.

Berndorff D, Borkowski S, Sieger S, Rother A, Friebe M, Viti F, Hilger CS, Cyr JE, Dinkelborg LM (2005) Radioimmunotherapy of solid tumors by targeting extra domain B fibronectin: identification of the best-suited radioimmunoconjugate. Clin Cancer Res 11(19 Pt 2): 7053s-7063s.

Berndt A, Kollner R, Richter P, Franz M, Voigt A, Borsi L, Giavazzi R, Neri D, Kosmehl H (2010) A comparative analysis of oncofetal fibronectin and tenascin- $\mathrm{C}$ incorporation in tumour vessels using human recombinant SIP format antibodies. Histochem Cell Biol 133(4): 467-475.

Bertilaccio MT, Grioni M, Sutherland BW, Degl'Innocenti E, Freschi M, Jachetti E, Greenberg NM, Corti A, Bellone M (2008) Vasculature-targeted tumor necrosis factor-alpha increases the therapeutic index of doxorubicin against prostate cancer. Prostate 68(10): 1105-1115.

Borsi L, Balza E, Carnemolla B, Sassi F, Castellani P, Berndt A, Kosmehl H, Biro A, Siri A, Orecchia P, Grassi J, Neri D, Zardi L (2003) Selective targeted delivery of TNFalpha to tumor blood vessels. Blood 102(13): 4384-4392.

Borsi L, Castellani P, Allemanni G, Neri D, Zardi L (1998) Preparation of phage antibodies to the ED-A domain of human fibronectin. Exp Cell Res 240(2): 244-251.

Clark MA, Fisher C, Judson I, Thomas JM (2005) Soft-tissue sarcomas in adults. N Engl J Med 353(7): 701-711.

Curnis F, Arrigoni G, Sacchi A, Fischetti L, Arap W, Pasqualini R, Corti A (2002) Differential binding of drugs containing the NGR motif to CD13 isoforms in tumor vessels, epithelia, and myeloid cells. Cancer Res 62(3): $867-874$.

Dang LH, Bettegowda C, Huso DL, Kinzler KW, Vogelstein B (2001) Combination bacteriolytic therapy for the treatment of experimental tumors. Proc Natl Acad Sci USA 98(26): 15155-15160.

Ebbinghaus C, Ronca R, Kaspar M, Grabulovski D, Berndt A, Kosmehl H, Zardi L, Neri D (2005) Engineered vascular-targeting antibodyinterferon-gamma fusion protein for cancer therapy. Int J Cancer 116(2): 304-313.

Eggermont AM, Schraffordt Koops H, Klausner JM, Schlag PM, Kroon BB, Ben-Ari G, Lejeune FJ (1997) Isolated limb perfusion with high-dose tumor necrosis factor-alpha for locally advanced extremity soft tissue sarcomas. Cancer Treat Res 91: 189-203.

Erba PA, Sollini M, Orciuolo E, Traino C, Petrini M, Paganelli G, Bombardieri E, Grana C, Giovannoni L, Neri D, Menssen HD, Mariani G (2012) Radioimmunotherapy with radretumab in patients with relapsed hematologic malignancies. J Nucl Med 53(6): 922-927.

Ferrari S, Casali P, Blay J, Tonini G, Le Cesne A, ALi N, Perfetti V, Palmerini E, Plalassini E, Ray-Coquard I, Vincenzi B, Domont J, Marchesi E, Marrari A, Cassier P, Silletta M, Stacchiotti S, Lambiase A, Bordignon C (2013) Two doses of NGR-hTNF (N) given alone or in combination with doxorubicin (D) in soft tissue sarcomas (STS). J Clin Oncol 31: 10568.

Frey K, Fiechter M, Schwager K, Belloni B, Barysch MJ, Neri D, Dummer R (2011) Different patterns of fibronectin and tenascin- $\mathrm{C}$ splice variants expression in primary and metastatic melanoma lesions. Exp Dermatol 20(8): 685-688.

Hoogenboom HR, Winter G (1992) By-passing immunisation. Human antibodies from synthetic repertoires of germline $\mathrm{VH}$ gene segments rearranged in vitro. J Mol Biol 227(2): 381-388.

Kita H, He XS, Gershwin ME (2003) Application of tetramer technology in studies on autoimmune diseases. Autoimmun Rev 2(1): 43-49.

Kontermann RE (2012) Antibody-cytokine fusion proteins. Arch Biochem Biophys 526(2): 194-205.

Lejeune FJ, Lienard D, Matter M, Ruegg C (2006) Efficiency of recombinant human TNF in human cancer therapy. Cancer Immun 6: 6.

Marlind J, Kaspar M, Trachsel E, Sommavilla R, Hindle S, Bacci C, Giovannoni L, Neri D (2008) Antibody-mediated delivery of interleukin-2 to the stroma of breast cancer strongly enhances the potency of chemotherapy. Clin Cancer Res 14(20): 6515-6524.

Massa PE, Paniccia A, Monegal A, de Marco A, Rescigno M (2013) Salmonella engineered to express CD20-targeting antibodies and a drug-converting enzyme can eradicate human lymphomas. Blood; doi:10.1182/blood-201212-474098.

Mortara L, Balza E, Sassi F, Castellani P, Carnemolla B, De Lerma Barbaro A, Fossati S, Tosi G, Accolla RS, Borsi L (2007) Therapy-induced antitumor vaccination by targeting tumor necrosis factor alpha to tumor vessels in combination with melphalan. Eur J Immunol 37(12): 3381-3392.

Moschetta M, Pretto F, Berndt A, Galler K, Richter P, Bassi A, Oliva P, Micotti E, Valbusa G, Schwager K, Kaspar M, Trachsel E, Kosmehl H, Bani MR, Neri D, Giavazzi R (2012) Paclitaxel enhances therapeutic efficacy of the F8-IL2 immunocytokine to EDA-fibronectin-positive metastatic human melanoma xenografts. Cancer Res 72(7): 1814-1824.

Nilsson F, Kosmehl H, Zardi L, Neri D (2001) Targeted delivery of tissue factor to the ED-B domain of fibronectin, a marker of angiogenesis, mediates the infarction of solid tumors in mice. Cancer Res 61(2): $711-716$.

Olieman AF, van Ginkel RJ, Hoekstra HJ, Mooyaart EL, Molenaar WM, Koops HS (1997) Angiographic response of locally advanced soft-tissue sarcoma following hyperthermic isolated limb perfusion with tumor necrosis factor. Ann Surg Oncol 4(1): 64-69.

Palumbo A, Hauler F, Dziunycz P, Schwager K, Soltermann A, Pretto F, Alonso C, Hofbauer GF, Boyle RW, Neri D (2011) A chemically modified antibody mediates complete eradication of tumours by selective disruption of tumour blood vessels. Br J Cancer 104(7): 1106-1115.

Papadia F, Basso V, Patuzzo R, Maurichi A, Di Florio A, Zardi L, Ventura E, Gonzalez-Iglesias R, Lovato V, Giovannoni L, Tasciotti A, Neri D, Santinami M, Menssen HD, De Cian F (2012) Isolated limb perfusion with the tumor-targeting human monoclonal antibody-cytokine fusion protein L19-TNF plus melphalan and mild hyperthermia in patients with locally advanced extremity melanoma. J Surg Oncol 107(2): 173-179.

Pasche N, Neri D (2012) Immunocytokines: a novel class of potent armed antibodies. Drug Discov Today 17(11-12): 583-590. 
Pasche N, Woytschak J, Wulhfard S, Villa A, Frey K, Neri D (2011) Cloning and characterization of novel tumor-targeting immunocytokines based on murine IL7. J Biotechnol 154(1): 84-92.

Pawelek JM, Low KB, Bermudes D (1997) Tumor-targeted Salmonella as a novel anticancer vector. Cancer Res 57(20): 4537-4544.

Pisters PW (2007) Treatment of localized soft-tissue sarcoma: lessons learned. Oncology 21(6): 731-732, 735.

Riedel RF (2012) Systemic therapy for advanced soft tissue sarcomas: highlighting novel therapies and treatment approaches. Cancer 118(6): 1474-1485.

Sacchi A, Gasparri A, Curnis F, Bellone M, Corti A (2004) Crucial role for interferon gamma in the synergism between tumor vasculature-targeted tumor necrosis factor alpha (NGR-TNF) and doxorubicin. Cancer Res 64(19): 7150-7155.

Santimaria M, Moscatelli G, Viale GL, Giovannoni L, Neri G, Viti F, Leprini A, Borsi L, Castellani P, Zardi L, Neri D, Riva P (2003) Immunoscintigraphic detection of the ED-B domain of fibronectin, a marker of angiogenesis, in patients with cancer. Clin Cancer Res 9(2): 571-579.

Sauer S, Erba PA, Petrini M, Menrad A, Giovannoni L, Grana C, Hirsch B, Zardi L, Paganelli G, Mariani G, Neri D, Durkop H, Menssen HD (2009) Expression of the oncofetal ED-B-containing fibronectin isoform in hematologic tumors enables ED-B-targeted 131I-L19SIP radioimmunotherapy in Hodgkin lymphoma patients. Blood 113(10): 2265-2274.

Schliemann C, Wiedmer A, Pedretti M, Szczepanowski M, Klapper W, Neri D (2009) Three clinical-stage tumor targeting antibodies reveal differential expression of oncofetal fibronectin and tenascin- $\mathrm{C}$ isoforms in human lymphoma. Leuk Res 33(12): 1718-1722.

Schwager K, Villa A, Rosli C, Neri D, Rosli-Khabas M, Moser G (2011) A comparative immunofluorescence analysis of three clinical-stage antibodies in head and neck cancer. Head Neck Oncol 3: 25.

Scoggins CR, Pisters PW (2008) Diagnosis and management of soft tissue sarcomas. Adv Surg 42: 219-228.

Spitaleri G, Berardi R, Pierantoni C, De Pas T, Noberasco C, Libbra C, González-Iglesias R, Giovannoni L, Tasciotti A, Neri D, Menssen HD, de Braud F (2013) Phase I/II study of the tumour-targeting human monoclonal antibody-cytokine fusion protein L19-TNF in patients with advanced solid tumours. J Cancer Res Clin Oncol 139(3): 447-455.

Starnes CO (1992) Coley's toxins in perspective. Nature 357(6373): 11-12.

Tijink BM, Perk LR, Budde M, Stigter-van Walsum M, Visser GW, Kloet RW, Dinkelborg LM, Leemans CR, Neri D, van Dongen GA (2009) (124) I-L19-SIP for immuno-PET imaging of tumour vasculature and guidance of (131)I-L19-SIP radioimmunotherapy. Eur J Nucl Med Mol Imaging 36(8): 1235-1244.

Villa A, Trachsel E, Kaspar M, Schliemann C, Sommavilla R, Rybak JN, Rosli C, Borsi L, Neri D (2008) A high-affinity human monoclonal antibody specific to the alternatively spliced EDA domain of fibronectin efficiently targets tumor neo-vasculature in vivo. Int J Cancer 122(11): 2405-2413.

This work is published under the standard license to publish agreement. After 12 months the work will become freely available and the license terms will switch to a Creative Commons AttributionNonCommercial-Share Alike 3.0 Unported License.

Supplementary Information accompanies this paper on British Journal of Cancer website (http://www.nature.com/bjc) 